\title{
Mean P Wave Duration
}

National Cancer Institute

\section{Source}

National Cancer Institute. Mean P Wave Duration. NCI Thesaurus. Code C62123.

The average (mean) duration (time) from the onset of atrial depolarization to the completion of atrial depolarization (leng th of the $\mathrm{P}$ wave), obtained from a set of measurements of the time from beginning to end of atrial depolarization. 